\title{
Sustained Knowledge Acquisition and Organizational Effectiveness: A Study of Manufacturing Firms Based in Rivers State, Nigeria
}

\author{
Edwinah Amah
}

\begin{abstract}
This study empirically examines the relationship between sustained knowledge acquisition and organizational effectiveness, with respondent managers drawn from 32 manufacturing firms in Rivers State. The study analyses the role of sustained knowledge acquisition in achieving optimal productivity, profitability and market share within the Nigerian socio-economic context. A triangulation of methodologies was adopted in the study, entailing a dominant nomothetic and a supportive ideographic approach. The aim was to adequately capture, not only the objective but the subjective stance of the respondents in the evaluation of the study variables. Our findings reveal a significant relationship between sustained knowledge acquisition and organizational effectiveness and in view of our results, the recommendations are made.
\end{abstract}

Keywords: Knowledge acquisition, effectiveness, change, market, survival

\section{Introduction}

Change is constant and inevitable; therefore the concern lies in adjusting to change. In the face of growing competition, the bestir of science and technology in product and service delivery, economic and political betoss, and the likes of which besiege the Nigerian socio-economic context, it behoves organizations to not only seek out ways of staying "afloat" but also tools for "setting the pace". And so the issue bothers on survivaland effectiveness throughquality knowledge acquisition, not at an instance but as a going concern. Knowledge can be acquired from external sources which include the employment of individuals with the required skills, competent and externally sourced training of existing staff in deficient areas, business alliances, data reports and market trends. According to Daud and Yusoff (2010) knowledge acquisition is concerned with the process of creating, generating, building and constructing knowledge. As an organizational activity, Kuhn et.al (1995) observed that it starts early and continues throughout the life span of the organization. It is a fundamental measure which facilitates effective learning and adaptability, thus enabling the survival of organizations through improved performance and service delivery.

The consistent acquisition and upgrade on knowledge, enables the organization to thrive through learning which as acknowledged by sexton et al. (1997) should be more content-oriented than processoriented.Holder et al. (2006) in theirstudy listed three basic components for the successful acquisition of knowledge. First, the need for organizations to focus on the characteristics of the problem at hand, second, the capacity to learn the necessary processes relating the observed characteristics to the categories of interest and finally, the capacity to learn by acquiring knowledge in an incremental and sustained manner that allows for changes in the previously adopted knowledge stance especially when such changes are crucial.

There is an avalanche of theoretical and empirical studies on knowledge acquisition and its effect on organizational effectiveness, with various findings on its antecedents and proposed benefits. Some include Daud and Yusoff (2010), who in their study empirically examined the effect of knowledge acquisition as a dimension of knowledge management on the organizational performance of SMEs. Their findings show a significant relationship between organizations with high knowledge managementprocesses and improved performance. Alvin and Heidi (1985), in their book "The Adaptive Corporation" stated various conditions necessitating the survival and prosperity of organizations, amongst these are various knowledge acquisition processes. Variousresearches have also focused on the role of knowledge acquisition, management and organizational adaptability(Davis and Nutley, 2000; Kotter and Heskett, 1992;Miller and Friesen, 1978;O'rielly, Chatman and Caldwell, 1991; Holder et al.,2006; Amah and Baridam, 2012).Despite these studies, little has been done with respect to sustained knowledge acquisition and organizational effectiveness within the Nigerian context, hence the existence of a lacuna which this study seeks to fill. This study as a point of departure from previous studies, examines the relationship betweensustained knowledge acquisition and organizational effectiveness in the Nigerian manufacturing industry.

\section{Literature Review}

Knowledge, according to McShanne and Von Glinow (2002) is a tool for understanding and coping with situations (external or internal) as experienced by the individual, group or corporate entity during the 
course of their interaction with the social and concrete world. As a dynamic construct, knowledge is multifaceted and complex, tacit and explicit, physical and abstract, static and evolving, instinctive and learned, collective and individual. Its development through sustained acquisition is as a result of the individual, group or organization's desire for continuous survival, growth, effectiveness and operational advantage (Nonaka, 1991; Inkpen, 1998).

Sustained knowledge acquisition is the process in which organizations; on a consistent and procedural basis; obtain useful information or knowledge peculiar to their interests. It is a process that entails an experiential or direct involvement, the vicarious or second hand experience from the activities of other organizations, or simply the congenital know-how of the founding fathers of the organization, in the acquisition of knowledge in the areas of concern. Such acquired knowledge is expected to further enhance the competitive stance of the organization through a strategic change in behaviour or a modification of systems and operations(Nonaka, 1991; Daft, 1998; Dimovski, 1994). Knowledge drives innovation and organizational adaptability, thus a sustained and continuous process of acquiring knowledge is fundamental to performance and effectiveness. Knowledge acquisition has also been linked to organizational operational efficiencyInkpen (1998), and serves as a spring board to various structural, cultural and organizational redesigns.It enhances the effectiveness of organizations through the acquisitionof current information which enables such organizations to further exploit their environment through the identification of competitive loop-holes and weaknesses.

Daud and Yusoff (2010) in their studyargue that knowledge; which is both declarative and procedural; is most effective when embedded in the practices, operations as well as the routines of the organization. Organizations therefore need to continually generate knowledge as this would facilitate the generation of new products and services to meet the requirements of the ever changing market, for as observed by McDougall and Oviatt (1995), the existing knowledge and capabilities of most firms are most times not applicable when entering new markets or environment, thus the need to acquire new knowledge on the basis of required behavioural change aimed at survival and effectiveness. Research shows that an organizations external experience affects its behaviour and performance, such experience includes various re-occurring interorganizational and networking activities which influence decisions thereby facilitating a dynamic switch in actions leading to adjustments in core functions and capabilities (Oviatt and McDougall, 2005; Lane and Lubatkin, 1998; Johanson\&Vahlne, 2003;).

Inkpen (1998) in his study emphasized on the role of the individual in the creation and utilization of knowledge but also argued that unless such knowledge is accessible, sustainable and transmittable between individuals and groups; such knowledge would have limited impact on organizational effectiveness. Thus, the process of knowledge acquisition is not only restricted to the search for knowledge but also the process whereby individual knowledge is constantly amplified and internalized into the knowledge base of the organization through sustained processes and efforts. Previous research show that a good way of maintaining consistency and process sustenance in an organization is to embed such a process into instituted policies, structures and system formats recognized by organizational members as binding and "part of the flow" (Daft, 1998; Denison, 1990; Amah, 2009). Knowledge grows relative to market changes, therefore organizations must realize the importance of "staying in touch" especially in this era of knowledge-based economies where knowledge is key and has changed the very essence of organizations.

Organizational Effectiveness; although a difficult, controversial and elusive construct to define; has been described by various researchers as the extent to which the organization is able to achieve its goals through the systematic application of acquired knowledge and resources (Quinn \&Rohrbaugh, 1983; Aydin \&Ceylan, 2009; Cummings \& Worley, 2004; Zheng et al., 2010). This description follows the goal model and approach to effectiveness (Daft, 1998; Cunningham, 2001) which has been adopted by this study as a means to measuring output levels and desired organizational outcomes(Cameron, 1984; Hall 1980). The rational goal approach, according to Amah and Baridam (2006) is based on the premise of goals, set by the organization and an assessment of how much or how well these goals have been achieved.

According to Cunningham (2001), Organizations are functionally rational when a set of activities such as; division of labour, organizational hierarchy, projects, programs, and functions to the overall goals of the organization are effectively defined, related and organized to achieve the goals of the organization. He argued that an organizations goal are identified by first establishing the general goal, a discovery and evaluation of the objective, means or tools for its accomplishments, and a definition of a set of activities for each objective. Thus, organizations are evaluated based on a comparison of planned activities and goals relative to actual accomplishments and achievement of those goals. Hall and Clark (1980) argue that in the consideration of goals and their measurements, operative goals are more important than official goals. In their opinion, the operative goals are more reflective of the organizations activities while official goals are abstract and elusive to measurement (Amah \&Baridam, 2012).

Effectiveness as an assessment of how well an organization achieves its goals allows for measurements in deciding the degree of this congruence between set goals and actual outcomes. Productivity, profitability and 
market share have been identified as indicators of effective organizations. As measures of organizational effectiveness, they are unique to each organization and focus on its operative goals (Aydin \&Ceylan, 2009; Amah, 2009). These measures are specific,capture the unique capabilities of each organization and are an expression of the individual outcomes of these organizations in the face of competition, change, and market growth.

Productivity is defined as the relationship betweenthe organizations units of input andoutput. It addresses the effective utilization of organizational inputs in the achievement of desirable levels of output. Productivity relates to how effectively and efficiently the organizations resources in terms of finance, time, talent, skill and materials are adequately applied in the production process so as to achieve desired output forms and products (Amah, 2006; Dabiran et al. 2010). As a measure of effectiveness, its emphasis is on the efficient distribution and allocation of the organizations resources so as to achieve optimalityin the outcome of product and service delivery. Amah (2006) observes that productivity as a measure of effectiveness is closely related to the concept of efficiency. While efficiency refers to the accomplishment of goals with minimum resources or waste and includes measures such as time minimization, cost minimization and waste minimization, effectiveness matches desired output level and quality withinput processes, time, resources and effort.

Profit has been identified as the core objective of most profit-making organizations as it necessitates survival and growth. It is an excess of revenue over expenses. It supplies managers and decision-makers within the organization with information signifying performance, effective processes and more efficient alternatives in the course of operations. It is an effective determinant of priceas costs of inputs are matched against the market price of outputs which form products and services (Fubara 1982; Flaboya, 2005; Malomo, 1999). As a measure of effectiveness, profitability is essential to organizational survival. It is the ability of an organization to generate and earn above what it spends on expenses and other costs. Profitability entails an organizations capacity for financial benefit as a result of its venture and operations in the course of offering a service or product and is the primary goal of all for-profit business ventures(Nickels et a. 1997; Amah, 2006; Edmonds et al. 2000). As a measure of effectiveness, profitability expresses the organizations profit generating ability by matching the organizations input costs with market values for products, thereby necessitating efficiency in productivity.

Market share is as a result of perceived product or service value. As one of the major objectives of the firm, it translates into profitability and growth. It is described as anorganization's sales revenue, derived from a particular marketand divided by the total sales revenue available in that same market (Czinkotaet al, 1997). A large market share in an industry is good evidence of revenue and profitability levels, this is observed by Welch (2003) in his study of the General Electric Company. In a highly competitive business environment, information remains the key to innovation and thus product distinction which is very important for customer satisfaction and business growth. Kotler and Armstrong (2001) argue that for organizations to be effective in competitive markets, firstly; they need to identify and address weak areas which could be exploited by competitors, secondly; they need to control production costs which in turn affect product prices. This is important as it plays a major role in customer choice and decisions, thirdly; consistent innovation through sustained information systems that allow for feedback, corrections and product improvement which invariably would translate into effectiveness and added customer value(McShane \& Von Glinow, 2003; Amah \&Baridam, 2006; Kotler \& Armstrong, 2001). From the foregoing the following hypotheses are derived:

$\mathrm{Ho}_{1}$ : There is no significant relationship between sustained knowledge acquisition and productivity

$\mathrm{Ho}_{2}$ : There is no significant relationship between sustained knowledge acquisition and profitability

$\mathrm{Ho}_{3}$ : There is no significant relationship between sustained knowledge acquisition and market share.

\section{Methodology}

The study adopts a concurrent triangulation of research methodologies which includes both nomothetic (quantitative) and ideographic (qualitative) approaches. As a correlational study, the cross sectional survey approach was adopted with analysis carried out at the micro level and the organization as the unit of analysis while data was generated from the managers in the target companies. Our sampling frame therefore consists of all management staff of the manufacturing industry, drawn from a population of 221 managers from 32 manufacturing companies registered with the manufacturers association of Nigeria, Rivers State chapter. The simple random sampling procedure was used in the selection of respondents and the sample size of 142 was estimated using the Taro Yamane's formula (Baridam, 2001). As a result of the data coding, editing and cleaning process, only 112 copies of the instrument were used for the quantitative analysis.

Two forms of data collection instruments were utilized, the questionnaire and structured in-depth interviews. Sustained knowledge acquisition was measured on a 7 -item instrument which served to illustrate various organizational knowledge acquisition sustaining processes, routines and formats. Each item is then scaled on a 5-point Likert scale ranging from (1) strongly disagree to (5) strongly agree which was used to indicate the level of respondent's disagreement or agreement with the listed items or indicators. The dependent 
variable, organizational effectiveness was operationalized through its measures; productivity, profitability and market share of which productivity was measured on a 2 -item instrument, profitability on a 5 -item instrument and market share on a 7-item instrument as adopted in Amah and Baridam (2012). All items were scaled on a 5point Likert scale of (1) strongly disagree to (5) strongly agree which was used to indicate agreement or disagreement levels relative to indicative statements reflecting the variables under study. The reliability tests for the instruments carry the following cronbach alpha coefficients: Sustained Knowledge Acquisition (0.88), Productivity (0.95), Profitability (0.93) and Market Share with (0.96). All representing acceptable values as Nunnaly (1978) posits through a model recommending a benchmark of $(0.70)$ for acceptable scales. As a result of the nature and distribution of the data, the Spearman's Rank Correlation Statistical tool was used in testing our hypotheses.

For our qualitative data, interviews were conducted on ten respondents drawn randomly from the sample. Questions bothering on the practice of knowledge acquisition, its policies and sustaining efforts as well as its relevance and role as a predictor of organizational survival and effectiveness especially in an environment as volatile as that of Nigeria, were brought under the subjective views of respondents. All responses and field recordings were later transcribed and saved in rich text formats (rtf), coded and analysed using the Nudist-vivo software (Onwuegbuzie and Collins, 2007; Onwuegbuzie and Johnson, 2010)

\section{Resultand Findings}

The quantitative analysis was carried out on two levels, the primary (Demographic and univariate) and secondary (Bivariate). Our primary analysis, which consisted of frequencies and descriptive analysis showed that for our demographic results, $32 \%$ of the respondents were female and $68 \%$ were male. $23 \%$ of the respondents had master degrees while the remaining $77 \%$ had only a first degree. $10 \%$ of the respondents had spent less than 10 years with their organizations, $85 \%$ had spent 10 to 20 years, and $5 \%$ had spent above 20 years. $15 \%$ of the respondents agree that their organizations have been in existence for less than 10 years, $64 \%$ agree theirs has been in existence for 10 to 20 years and $21 \%$ agree to an organizational existence above 20 years. For the organizational staff strength, $12 \%$ of the respondents agree that their organizations have less than 20 staff, $83 \%$ agree theirs is between 20 to 50 staff members while only $5 \%$ agree their staff strength is above 50. On availability of branch offices, $39 \%$ agreed to their organizations having branch offices while the remaining $61 \%$ did not have branch offices.

The result of the univariate analysis is shown in Table 1. With insufficient or weak mean scores (x) indicated from (1.0 to 2.0), barely sufficient or moderate mean scores indicated from (2.1 to 3.0), sufficient or high mean scores indicated from (3.1 to 4.0) and weighty or very high mean scores from (4.1 to 5.0).

Table 1. Descriptive Statistics of Study Variables

\begin{tabular}{lccccc}
\hline variables & $\mathbf{N}$ & Mean & Std. Deviation & \multicolumn{2}{c}{ Skewness } \\
\cline { 2 - 5 } & Statistic & Statistic & Statistic & Statistic & Std. Error \\
\hline Sustained Knowledge Acquisition & 112 & 3.9452 & .77686 & -1.945 & .228 \\
Productivity & 112 & 4.0472 & .79421 & -1.778 & .228 \\
Profitability & 112 & 4.0128 & .83179 & -2.013 & .228 \\
Market Share & 112 & 4.0969 & .78486 & -2.202 & .228 \\
Total No. of Respondents & 112 & & & \\
\hline
\end{tabular}

Source: SPSS output on research data analysis

The table illustrates a high and sufficient mean score (x) for all variables. As a pre-requisite for survival, especially within a context such as the Nigerian manufacturing industry, Sustained Knowledge acquisition carries a mean score of $(x=3.945)$ indicating respondents high level of agreement to the prevailing practice of sustained knowledge acquisition in their organizations. Similarly, respondents agree to high productivity levels in their organizations; this is reflected in the productivity mean score of $(x=4.047)$. Also, Profitability and market share hold mean scores of $(x=4.013)$ and $(x=4.0969)$ respectively, indicating respondents affirmation to the significant levels of the incidence of these various measures of effectiveness.

For our secondary (bivariate) analysis, the results are shown in table 2. All hypotheses are tested for significant relations based on $\mathrm{p}$ values. At a significance level of 0.05 , a $\mathrm{p}<0.05$ value indicates a significant relationship, therefore a rejection of a previously stated null hypothesis. While a $\mathrm{p}>0.05$ valueindicates a nonsignificant relationship therefore an acceptance of the null hypothesis. The rho values are indicative of the strength and direction of the relations between variables. 
Table 2. Spearman's Correlations and Hypotheses Tests

\begin{tabular}{lllccc}
\hline & & & Productivity & Profitability & Market Share \\
\hline \multirow{2}{*}{ Spearman's rho } & Sustained Knowledge & Correlation Coefficient & .337 & .766 & .714 \\
& Acquisition & Sig. (2-tailed) & .000 & .000 & .000 \\
& & $\mathrm{~N}$ & 112 & 112 & 112 \\
\end{tabular}

Source: SPSS output on research data analysis

The results show that sustained knowledge acquisition correlates significantly with productivity $($ rho $=$ $.337, \mathrm{p}<0.05)$; through the consistent and sustained acquisition of knowledge, manufacturing organizations are thus able to acquire current technological equipment, machinery and tools which would not only increase the capacity to produce more but would also produce at a more effective and efficient level. Such technology could be in the form of warehouse machinery, computer system upgrades, software programs, and even technical manpower know-how.Profitability ( products and services would become more marketable and customer-need-oriented, thereby increasing sales through increased value creation and optimal service delivery. Market share (rho $=.714, \mathrm{p}<0.05)$; when value is created and satisfaction obtained, the demand for products and services will increase thus leading to an expansion in customer base. This can only be made possible through an understanding of the market, product and service demands, competitive manoeuvres and customer expectations. Such knowledge changes with time just as population, technology and society does. To keep up, organizations need to remain informed, aware and in correspondence with the market.

The findings indicate stronger and more significant relations between sustained knowledge acquisition and profitability including Market share when compared to productivity. This could be as a result of constant product modifications, technological upgrades or product rebrands, stemming from organizational market adaptive steps through knowledge acquisition and utilization which may at certain points-in-time impinge on production operations or processes, but in the long run, still facilitate more efficient and effective production processes.Based on the foregoing, we therefore reject all previously stated hypotheses and restate that:

i. There is a significant relationship between sustained knowledge acquisition and productivity

ii. There is a significant relationship between sustained knowledge acquisition and profitability

iii. There is a significant relationship between sustained knowledge acquisition and market share.

For the qualitative analysis, responses were coded into nodes. Three nodes were created to represent the measures of effectiveness, namely; productivity, profitability and market share. Each node reflected an instance or prevailing outcome as a result of the effect, application or occurrence of a major contributing factor, which in the study is sustained knowledge acquisition. The directional arrows are used to portray the effect and define the nature of the relationship between sustained knowledge acquisition and the outcomes of an effective organization. Publications and documents which form the secondary data source as well as the interviews sourced primarily from the managers of these companies, were categorized and coded into the nodes. The analysis showed a highly favourable response rate in support of an existing relationship between sustained knowledge acquisition and organizational effectiveness.

Figure 1.shows the Nudist-vivo model output which is used to illustrate the result for the qualitative analysis which evaluates the relations between sustained knowledge acquisition and organizational effectiveness.

Fig 1. Nudist-vivo model of variable relationships

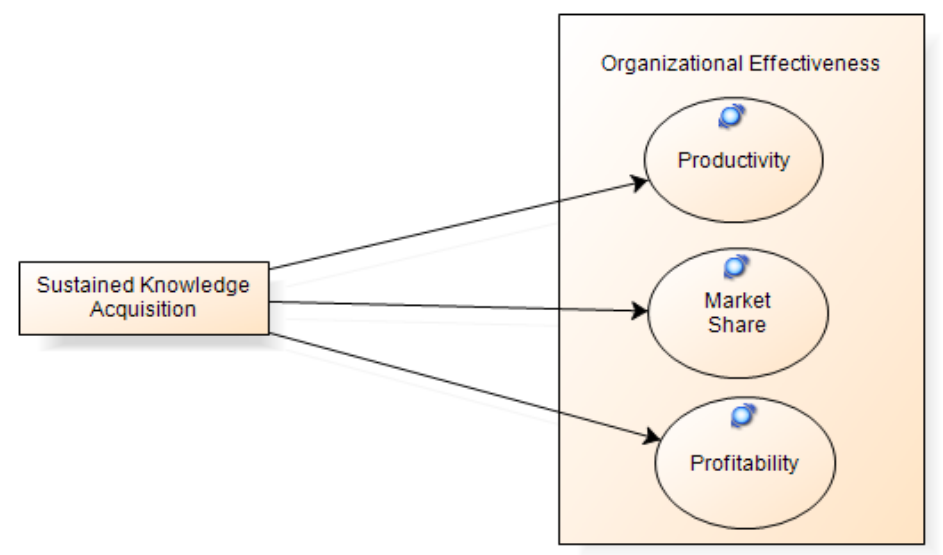


The qualitative analysis showed that most of the respondents agreed to the relevance of a sustained knowledge acquisition process in achieving organizational effectiveness but cited various hindrances. Some include; the funding, cost and follow-up of such processes. Also the non-inclusion or lack of the functionality of a research and development $(R \& D)$ department in most Nigerian manufacturing organizations poses a serious problem. Respondents affirm that through proper policy implementation and design, "tabs" can be kept on market and product changes as well as preferred product lines. The interviews also revealed that respondents believed strongly that without the sustained acquisition of knowledge, most of their products would have been considered obsolete and irrelevant in the market. Productivity, profitability and market share were all considered as outcomes of an effective utilization of acquired knowledge, which as noted from the responses, can only be of advantage if it is constantly up-dated, consistent with market trends and in-tune with customer demands.

\section{Discussionand Implications}

The purpose of this study was to investigate the relationship between sustained knowledge acquisition and organizational effectiveness, and to ascertain the effect of sustained knowledge acquisition on effective organizational outcomes such as productivity, profitability and market share.From the results we find that:

\subsection{Relationship between Sustained Knowledge Acquisition and Productivity}

The study finds thatthere is a significant and moderate relationship between sustained knowledge acquisition and productivity; although sustained knowledge acquisition is necessary for efficiency in productivity, it is possible that the application of such knowledge may at first seem "unsettling" for production operations which require certain levels of process consistency. Thesechanges may necessitate a total overhaul of some production machinery, tools or protocol but hold positive intentions aimed at futuristic adaptation and survival. Amah and Baridam (2012) in their study of adaptability and organizational effectiveness found that there was a negative and non-significant result between organizational adaptability and productivity but as pointed out, productivity which is the measure of how effectively and efficiently inputs are transformed into outputs, would not be possible without the necessary knowledge or skill to achieve required levels of efficiency and effectiveness (Amah, 2006; Garvin, 1998 Clark and Fujimoto, 1991). Knowledge is necessary to be productively efficient and effective, and such knowledge has to be consistent and in line with contemporary technology, business outlook and operations as well as operational methods.

\subsection{Relationship between Sustained Knowledge Acquisition and Profitability}

The study finds that there is a significant and strong relationship between sustained knowledge acquisition and profitability. Profitability which is an essential objective for all for-profit organizations is an important indicator of business performance and effectiveness without which such businesses cannot survive (Amah, 2006). It is the ability of the organization to generate profit as a result of the sales of its products and services which of course would not be possible if value is not created and "needs" are not met. As a result of the sustained acquisition of knowledge, businessescan thrive by producing marketable products and services which hold value and meet customer need.

Sustained knowledge acquisition also ensures product superiority and standard exceptionality which is a major drive for profitability and thus organizational performance. Due to the unpredictable nature of business environments, the ever growing pace of competition and market disequilibria, it is important that organizations adopt a system of norms, policies or beliefs that would support the organizations capacity to acquire, interpret and transfer knowledge from the environment into internal behavioural patterns, thereby necessitating changes which would increase its chances of survival, profitability and development (D'Aveni 1994; Daft, 1998; Amah and Baridam, 2012).

\subsection{Relationship between Sustained Knowledge Acquisition and Market Share}

The study finds that there is a significant and strong relationship between sustained knowledge acquisition and market share. Organizations can only grow and develop through its position and place in its market affairs. Market share spells out the prominence and recognition placed on the organization; an advantage which undoubtedly would be most beneficial to the organization and which adequately signifies its performance and effectiveness (McShane \& Von Glinow, 2003; Amah, 2009). Organizations can only grow and attain significance through an understanding of the market. It is important that managers strengthen their knowledge base through a systematic information "check-up" routine that would further facilitate the renewal of production processes, product designs and packaging, work methods, and service delivery. To grow and be significant, organizations must learn to evolve and to be relevant in the market by acquiring useful and necessary information on trends and market behaviour. 


\section{Conclusionsand Recommendations}

Knowledge is dynamic and ever changing. To survive and thrive, organizations must on a continuous basis, acquire relevant knowledge. As a rejuvenating tool, knowledge propels the organization to heights which can only sustained through a constant re-evaluation of its knowledge base relative to the changes in the environment and the nature of the competition. Through sustained knowledge acquisition, organizations can effectively manage their resources, maintain optimal operational standards and achieve high levels of productivity, profitability and market share.

Based on the result of this study, it is recommended that organizations adopt a sustained knowledge acquisition culture, practical enough to match the ever changing market demands, reliable enough to predict to a considerable degree certain unforeseen environmental occurrences, suitable enough to be utilized and implemented by the organization in such systematic ways that allow for improvements and up-grades on already existing technological systems and operational processes, and finally, relevant enough to serve as an advantage upon which the organization can uniquely attain its purpose and specified objectives.

\section{References}

[1]. Amah, E. (2006) Human Resource Management.Amethyst Publishers Port Harcourt.

[2]. Amah, E. (2009) Corporate Culture and Organizational Effectiveness: A Study of the Nigerian Banking Industry. An Unpublished $\mathrm{PhD}$ Thesis of the Faculty of Management Sciences, University of Port Harcourt, Nigeria.

[3]. Amah, E. \&Baridam, D. (2012) Adaptability and Organizational Effectiveness: A Study of the Nigerian Banking Industry, International Journal of Business and Management Tomorrow, 2 (3).

[4]. Aydin, B. Ceylan, A. (2009) The role of Organizational Culture on Effectiveness. Ekonomika Management.

[5]. Baridam, D.M. (2001). Research methods in administrative sciences. Port Harcourt, Nigeria: University of Port Harcourt Publishing House.

[6]. Bruneel, J. Yli-Renko, H. Clarysse, B. (2010) learning from experience and learning from others: how congenital and interorganizational learning substitute for experiential learning in young firm internationalization. Strategic Entrepreneurship Journal, 164-182, Wiley.

[7]. Cameron, K. S. (1984). The effectiveness of ineffectiveness.In B. M. Staw\& L. L. Cummings (Eds.) Research in organizational behavior (Vol. 6, pp. 276). Greenwich, CT: JAI Press.

[8]. Clark, K. and Fujimoto, T. (1991) Product Development Performance, Boston: Harvard Business School Press.

[9]. Clark, K. B and Fujimoto, T (1991) Product Development Performance Strategy, Organization and Management in the World Auto industry. Boston: Harvard Business School Press.

[10]. Cummings, T.G and Worley, C.O (1993) Organization Development and Change $5^{\text {th }}$ Ed: New York; West Publishing Company.

[11]. Cunningham (2001) Approaches to the evaluation of organizational effectiveness. University of Victoria.

[12]. Czinkota, M.R, Ketabe M and Mercer, D (1997) Marketing Management. Blackwell Publishers, UK.

[13]. D’Aveni, R. A (1994) Hyper competition - Managing the Dynamics of Strategic Maneuvering. New York, Free Press.

[14]. Dabirian, S. Rezvanfar, A. Asadi, A. (2010) The Influence of Organizational Factors on Individual Productivity of Agricultural Extension Experts. Asian Journal of Agricultural Sciences 2(3): 78-83, Maxwell Scientific Organization.

[15]. Daft, R.L (1998)Organization Theory and Design, $6^{\text {th }}$ Ed, South-western.

[16]. Daud, S. Yusoff, F. (2010) Knowledge Management and Firm Performance in SMEs: The role of Social Capital as a Mediating Variable. Asian Academy of Management Journal Vol. 15, No. 2, 135-155.

[17]. Davis, H. T. O. and Nutley, S. M (2000)Developing Learning Organization in the National Health Service. British Medical Journal April

[18]. Denison, D.R. and Mishra, A.K (1995) 'Toward a theory of Organizational Culture and Effectiveness' Organizational Science 6: 204-223

[19]. Denison, D. (2000) "Organizational culture: Can it be a key lever for driving The Handbook of Organizational Culture. London. Culture and organizational effectiveness: Is Asia different from the rest of the world?" Organizational Dynamics, 33(1) 98-109.

[20]. Denison, D. Hooijberg, R. and Quinn, R. (1995) "Paradox and performance: Toward a theory of behavioral complexity in managerial leadership." Organization Science 6(5) 524-540.

[21]. Denison, D.R. (1990) Corporate Culture and Organizational Effectiveness: New York.

[22]. Denison, D.R., Lief, C. and Ward, J.L. (2004) "Culture in family-owned enterprises: Recognizing \& leveraging unique strengths." Family Business Review, 17(1) 61-70.

[23]. Dimovski, V. (1994) Organizational Learning and Competitive Advantage: A Theoretical and Empirical Analysis.An Unpublished Thesis, Cleaveland State University.

[24]. Edmonds, T.P. Edmonds, C.D and Tsay, B. (2000) Fundamental Managerial Accounting Concepts Boston: Irwin McGraw-Hill p.7

[25]. Flaboya O.J. (2005) Modern Practice of Banking, Rehlz Printers.

[26]. Fubara B.A (1982) Business Policy on Governement-Owned Companies in Less Developed Countries: The Nigerian Experience. Ph.D Thesis Strathclyde Business School University of Strathclyde, Glasgow pp $1-85$.

[27]. Garvin, D.A (1988) Managing Quality. New York Free Press

[28]. Hall, R. (1980). Effectiveness Theory and Organizational Effectiveness. Journal of Applied Behavioral Science, 16, 536-545.

[29]. Hall, R.H and Clark, J.P (1980) "An Ineffective Effectiveness Study and Some Suggestions For Future Research," Sociological Quarterly 21:119-34.

[30]. Holder, L. Markov, Z. Russell, I. (2006) Advances in Knowledge Acquisition and Representation.International Journal on Artificial Intelligence Tools. World Scientific Publishing Company.

[31]. Inkpen, C.A (1998) Learning and Knowledge Acquisition through International Strategic Alliances. Academy of Management Executive, Vol. 12, No. 4

[32]. Johanson, J. Vahlne E. (2003) Business relationship learning and commitment in the internationalisation process. Journal of International Entrepreneurship 1: 83-101.

[33]. Johnson, R. B. and Onwuegbuzie, A. J. (2010).Mixed research. In R. B. Johnson \& L. B. Christensen, Educational research: Quantitative, qualitative, and mixed approaches (4th ed., pp. 439-459). Thousand Oaks, CA: Sage.

[34]. Kotler P and Armstrong G. (2001) Principles of Marketing $9^{\text {th }}$ ed. Prentice Hall. 
[35]. Kotter, J. P. and J. L. Heskett (1992) Corporate Culture and Performance. New York: The Free Press.

[36]. Kuhn .D., Garcia-Mila .M., Zohar .A., Andersen .C., White .S.H, Klahr D, Carver S.M (1995) Strategies of Knowledge Acquisition. Monographs of the Society for Research in Child Development, Vol. 60, No. 4: Blackwell Publishing.

[37]. Lane PJ, Lubatkin M. (1998) Relative absorptive capacity and interorganizational learning. Strategic Management Journal 19(5): $461-477$.

[38]. Lee, J.S.Y (1999) "Organizational Learning in China” Business Horizons.wiley.

[39]. Malomo, M. (1999) Management Accounting with Application of Quantitative Techniques.Ikeja: Chinedum Publishers Ltd, p.49 and pp. $169-200$.

[40]. Manufacturers Association of Nigeria (MAN), Rivers State / Bayelsa State Directory.http://phmanufacturersnigeria.org/

[41]. McShane, S.L. and Von Glinow, M.A (2003) Organizational Behaviour. Emerging Realities For The Workplace Revolution. $2^{\text {nd }}$ ed. McGraw Hill Companies Inc.

[42]. Miller, D. and Friesen, P.H. (1978) 'Archetypes of Strategy Formulation'. Management Science, Vol. 24, No. 9, pp. 921-933

[43]. Nickels, G. McHugh, J.M. and McHugh, S.M. (1997) Understanding Business. $4^{\text {th }}$ ed. Irwin McGraw-Hill New York.

[44]. Nonaka, I. (1991) The knowledge-creating company. Harvard Business Review, 69 (6), 96-104.

[45]. Nunnally, J. C. (1978) Psychometric theory (2nd Ed.). NY: Mc-Graw Hill.

[46]. O'Reilly, C. A. Chatman, J. and Caldwell, D. F. (1991).People and Organizational Culture.The Academy of Management Journal, 34 (3), 487-516.

[47]. Onwuegbuzie, A. J. and Collins, K. M. T. (2007) A typology of mixed methods sampling designs in social science research. The Qualitative Report, 12, 281-316. Retrieved from http://www.nova.edu/ssss/QR/QR12-2/Onwuegbuzie2.pdf

[48]. Oviatt, B.M. McDougall, P.P. (1995) Global start-ups: entrepreneurs on a worldwide stage. Academy of Management Executive 9: $30-44$.

[49]. Oviatt, B.M. McDougall, P.P. (1997) Challenges for internationalization process theory: the case of international new ventures. Management International Review 2(37): 85-99.

[50]. Oviatt, B.M. McDougall, P.P. (2005) Defining international entrepreneurship and modelling the speed of internationalization. Entrepreneurship Theory and Practice 24: 537-553.

[51]. Quinn, R.E. Rohrbaugh, J. (1983), A spatial model of effectiveness criteria: towards a competing values approach to organisational effectiveness, Journal of Management Science, 29 363-7.

[52]. Schein E. H., "What is culture", in P. J. Frost, L. F. Moore, M. R. Louis, C. C. Lundberg, \& J. Martin (Eds.), Reframing organizational culture, Newbury Park, CA: Sage, 1991, pp. 243-253.

[53]. Schein, E. H. (1985). Organizational culture and leadership: A dynamic view. San Francisco, CA: Jossey-Bass.

[54]. Sexton, D. L. Upton, N.B. Wacholtz, L.E. and McDougall, P.P. (1997) Learning needs of growth oriented entrepreneurs. Journal of Business Venturing 12 (1):1-8.

[55]. Tofler, A. and Tofler, H. (1985) TheAdaptive Corporation. McGraw-Hill.

[56]. Welch P.N (2003) Measuring cost efficiency in Manufacturing Firms: A comparison of Techniques. Journal of Productivity Analysis, Volume 17, p.123-151.

[57]. Zheng, W. Yang, B. and McLean, G. N (2010) Linking organizational culture, structure, strategy, and organizational effectiven ess: Mediating role of knowledge management Journal of Business Research Volume 63, Issue 7, Pages 763-771 